\title{
Metabolism of Steroid and Amino Acid Moieties of Conjugated Bile Acids in Man
}

\author{
I. CHOLYLGLYCINE
}

\author{
Gershon W. Hepner, Alan F. Hofmann, and Paul J. Thomas \\ From the Gastroenterology Unit, Mayo Clinic and Mayo Foundation, \\ Rochester, Minnesota 55901
}

\begin{abstract}
A в S T R A C T Cholyl-2,4- ${ }^{8} \mathrm{H}$-glycine- $1-{ }^{14} \mathrm{C}$ was administered orally to eight healthy subjects with indwelling nasoduodenal tubes. The distribution of radioactivity among bile acids and the specific activity of cholylglycine were determined in bile collected at intervals for 7 days. ${ }^{8} \mathrm{H}$ and ${ }^{14} \mathrm{C}$ were measured in stool. ${ }^{14} \mathrm{C}$ in breath was calculated from interval ${ }^{14} \mathrm{CO}_{2}$ specific activity determinations.

The daily fractional turnover of the glycine moiety (mean \pm SE, $106 \pm 17 \%$ ) was three times greater than that of the cholyl moiety $(38 \pm 7 \%)$. On the basis of certain assumptions, it was calculated that about $18 \%$ of the cholylglycine pool was deconjugated per enterohepatic cycle. The extent of deconjugation appeared to be unrelated to the efficiency of absorption of the cholyl moiety, which averaged $90-95 \%$ per enterohepatic cycle. ${ }^{14} \mathrm{C}$ was recovered predominantly in breath $(52 \pm 5 \%$ of administered dose), and $24 \mathrm{hr}{ }^{14} \mathrm{CO}_{2}$ excretion correlated highly $(r=0.95)$ with daily fractional turnover of the glycine moiety. ${ }^{3} \mathrm{H}$ excretion occurred predominantly in feces, and the rate correlated highly $(r=0.92)$ with the daily fractional turnover of the cholyl moiety. Deoxycholylglycine became labeled with ${ }^{3} \mathrm{H}$ rapidly, indicating the occurrence of bacterial 7-dehydroxylation of the cholyl moiety and absorption of deoxycholic acid. This biotransformation occurred in all eight subjects but varied in degree and was unrelated to the degree of deconjugation. Since ingested glycine- $1-{ }^{14} \mathrm{C}$ was not incorporated into bile acid glycine, appearance of ${ }^{11} \mathrm{C}$ in deoxycholylglycine (observed in three of eight subjects) indicated that 7-dehydroxylation of cholylglycine can occur without deconjugation. Dehydroxylation was also observed in vitro when fecal homogenates were incubated with cholylglycine.
\end{abstract}

Received for publication 20 December 1971 and in revised form 28 February 1972.

\section{INTRODUCTION}

In man, bile acids are excreted by the liver as conjugates of glycine and taurine (1). Although the metabolism of the steroid moiety has been well defined in man, that of the amino acid moiety is imperfectly understood.

Norman (2) administered cholyl-24- ${ }^{14} \mathrm{C}$-glycine-1 ${ }_{-1}^{14} \mathrm{C}$ to patients recovering from cholecystectomy for cholelithiasis and, on the basis of ${ }^{14} \mathrm{C}$ recovery in bile acids isolated from bile samples obtained $24 \mathrm{hr}$ later, concluded that the cholyl moiety was conserved more than the glycine moiety. Because subjects with cholelithiasis may have a decreased bile acid pool, Norman's data may not apply to healthy subjects. Furthermore, because both moieties of cholylglycine were labeled with ${ }^{14} \mathrm{C}$, the bile acids had to be analyzed before and after hydrolysis to permit assignment of radioactivity to individual conjugated bile acids. Garbutt, Wilkins, Lack, and Tyor (3) assessed the rate of deconjugation and 7-dehydroxylation of cholyl-24- ${ }^{14} \mathrm{C}$-taurine during enterohepatic cycling but, since only the steroid moiety was labeled, they were unable to study the fate of the amino acid moiety.

Development of a method for preparing bile acids with a stable ring tritium label (4) enabled us to make cholyl-2,4- ${ }^{3} \mathrm{H}$-glycine and to compare its metabolism as well as its mode of excretion with that of simultaneously administered cholylglycine- $1-{ }^{14} \mathrm{C}$.

\section{METHODS}

Carefully informed consent was obtained from all subjects. Complete studies were performed on eight healthy subjects $\left(\mathrm{C}_{1}\right.$ through $\left.\mathrm{C}_{8}\right)$, and selected observations were made on a ninth subject $\left(\mathrm{Gb}_{\theta}\right)$ who had had a cholecystectomy years previously. On the morning on which the study commenced, a nasoduodenal tube was passed. Its tip was positioned, with the aid of fluoroscopy, at the duodenojejunal flexure, and the tube remained in position for $168 \mathrm{hr}$. During the study, the subjects carried out their usual activity and were instructed to eat three meals per day. 
Cholic-2,4- ${ }^{3} \mathrm{H}$ acid was prepared from methyl 3-keto-7 $\alpha$, $12 \alpha$-dihydroxy-5 $\beta$-cholanoate (4) and conjugated with glycine methyl ester (5). The reaction mixture was purified by column chromatography using silicic acid and a gradient of methanol in chloroform. Fractions containing pure cholylglycine methyl ester were pooled, and reduced to dryness on a rotary evaporator. The residue was dissolved in ethanol: $1 \mathrm{~N} \mathrm{NaOH}(1: 1, \mathrm{v} / \mathrm{v})$ and left at room temperature overnight. The $\mathrm{pH}$ was then adjusted to neutrality with $5 \mathrm{~N}$ $\mathrm{HCl}$; the solution was evaporated to dryness, and the residue was dissolved in chloroform: methanol $(2: 1, \mathrm{v} / \mathrm{v})$. The final $\mathrm{SA}$ was $3.4 \mathrm{mCi} / \mathrm{mmole}$. Glycine- $1-{ }^{14} \mathrm{C}$ methyl ester was conjugated with cholic acid to yield cholylglycine- $1-{ }^{14} \mathrm{C}$ methyl ester of SA $0.5-1 \mathrm{mCi} / \mathrm{mmole}$. The reaction product was purified by column chromatography using silicic acid and a gradient of methanol in chloroform for elution. The radiopurity was assessed by zonal scanning of thin-layer chromatograms. Radiopurity of both compounds was greater than $95 \%$.

Fasting subjects were given $10 \mu \mathrm{Ci}$ of cholylglycine- $1-{ }^{14} \mathrm{C}$ and $25 \mu \mathrm{Ci}$ of cholyl-2,4- ${ }^{3} \mathrm{H}$-glycine in a milk shake. The radiation exposure from $10 \mu \mathrm{Ci}$ of cholylglycine- $1-{ }^{14} \mathrm{C}$ is calculated as less than $10 \%$ of that received from natural and cosmic sources. Samples of duodenal bile were taken during the next $168 \mathrm{hr} ; 2 \mathrm{ml}$ of bile was removed after the intravenous administration of $37.5 \mathrm{U}$ of cholecystokinin (supplied by Dr. E. Jorpes, Karolinska Institute, Stockholm, Sweden). The samples were collected in $20 \mathrm{ml}$ of ethanol, heated to precipitate protein, filtered, and then dried. The residue was dissolved in $0.5 \mathrm{ml}$ of methanol and stored at $4^{\circ} \mathrm{C}$.

Portions of bile were counted in a dioxane-based solvent system, and ${ }^{3} \mathrm{H}$ and ${ }^{14} \mathrm{C}$ contents were determined by using external standards. The ${ }^{3} \mathrm{H}:{ }^{14} \mathrm{C}$ ratio became imprecise after $120 \mathrm{hr}$ because of the rapid decrease in ${ }^{14} \mathrm{C}$.

A second portion of bile was analyzed by zonal scanning (6) to determine the distribution of radioactivity among individual bile acid conjugates. The disintegrations per minute (dpm) in each $4 \mathrm{~mm}$ section were plotted to give a histogram indicating the percentage radioactivity $\left({ }^{3} \mathrm{H}\right.$ and ${ }^{14} \mathrm{C}$ ) in each component. Reference compounds were chromatographed simultaneously and radioactivity was assigned to cholylglycine, deoxycholylglycine, or conjugates of taurine; cholyltaurine and deoxycholyltaurine were not separated. These data indicated not only the distribution of radioactivity among bile acid classes but also the ${ }^{3} \mathrm{H}:{ }^{14} \mathrm{C}$ ratio in cholylglycine.

A third portion of bile was chromatographed on a $20 \times 25$ $\mathrm{cm}$ silicic acid plate; cholylglycine standards were run on either side of the bile portion. The region of the plate containing cholylglycine was scraped off and eluted with 0.1 $\mathrm{ml}$ of methanol, $1 \mathrm{ml}$ of hydrazine hydrate (1 $\mathrm{M}, \mathrm{pH} 9.5)$, and $1 \mathrm{ml}$ of phosphate buffer $(0.1 \mathrm{M}, \mathrm{pH} 9.5)$. One-half of the sample was analyzed for bile acid mass using the hydroxysteroid dehydrogenase method (7), and the remaining half was counted for radioactivity to yield the specific activity of cholylglycine in terms of both ${ }^{3} \mathrm{H}$ and ${ }^{14} \mathrm{C}$. Samples were run in duplicate; the coefficient of variation was $7 \%$. Because of the rapid decrease of ${ }^{14} \mathrm{C}$ specific activity in cholylglycine, valid specific activity for the glycine moiety could not be determined for five subjects after $72 \mathrm{hr}$ and for seven subjects after $120 \mathrm{hr}$.

To determine whether liberated glycine- $1-{ }^{14} \mathrm{C}$ might be absorbed and reincorporated into cholylglycine, one subject ( $\left.\mathrm{C}_{6}\right)$ was given glycine- $1-{ }^{14} \mathrm{C}(20 \mu \mathrm{Ci})$ by mouth; bile sam- ples were collected after 6 and $24 \mathrm{hr}$ and examined by zonal scanning for the presence of cholylglycine- $1-{ }^{14} \mathrm{C}$.

Bile acid kinetics were calculated according to a firstorder kinetic model (8). The equation for the specific activity decay curve of cholyl-2,4- ${ }^{3} \mathrm{H}$-glycine was calculated by a least-squares computer program; the linearity of the logarithmic specific activity decay was indicated by a correlation coefficient greater than 0.96 for all studies. Cholyl2,4- ${ }^{3} \mathrm{H}$-glycine specific activity at time zero was obtained by extrapolation, and the dose of radioactivity administered was divided by this value to give the pool size. The slope of the $\log$ specific-activity decay curve is the rate constant or fractional turnover. Cholylglycine- $1-{ }^{14} \mathrm{C}$ specific activities were multiplied by 2.5 to correct for the smaller dose of administered radioactivity. The adjusted specific activities of cholylglycine- $1-{ }^{14} \mathrm{C}$ at $6,24,48$, and $72 \mathrm{hr}$, together with the specific activity of cholylglycine at time zero (calculated from decay of cholyl-2,4- ${ }^{3} \mathrm{H}$-glycine), were used to calculate a specific activity decay curve for the glycine moiety; this curve intercepted the ordinate at the same place as that of cholyl-2,4- ${ }^{3} \mathrm{H}$-glycine. The half-lives of the cholyl-2,4- ${ }^{3} \mathrm{H}$ and glycine- $1-{ }^{14} \mathrm{C}$ moieties were determined from the equation $\mathrm{t}_{\frac{1}{3}}=\log _{\mathrm{e}} 0.5 / \mathrm{K}$ ( $\mathrm{t}_{\frac{1}{3}}$ is half-life, and $\mathrm{K}$ is daily fractional turnover). The daily syntheses of the cholyl and glycine moieties of cholylglycine were obtained by multiplying the pool (millimoles) by the rate constant $\left(\right.$ days $\left.^{-1}\right)$. In all calculations of glycine kinetics it was assumed that reincorporation of liberated glycine $-1-{ }^{14} \mathrm{C}$ into the glycine moiety of bile acids was negligible (Results).

At $3,6,12,24,48,72,120$, and $168 \mathrm{hr}$ after administration of the dose, the subjects exhaled forcibly into duplicate liquid scintillation vials containing $4.0 \mathrm{ml}$ of $1 \mathrm{M}$ Hyamineethanol, $1: 1(\mathrm{v} / \mathrm{v})$, with thymolphthalein as indicator $(9$, $10)$, until neutralization was indicated by the indicator turning from blue to colorless. Samples were counted in a toluene-based scintillation mixture and converted to dpm by external standardization. Because each counting vial contained 2 mmoles of $\mathrm{CO}_{2}$, the radioactivity could be expressed as disintegrations/minute per millimole $\mathrm{CO}_{2}$. The cumulative excretion of ${ }^{14} \mathrm{C}$ was calculated by multiplying the mean $\mathrm{CO}_{2}$ specific activity for each time interval by the endogenous production of $\mathrm{CO}_{2}(9 \mathrm{mmoles} / \mathrm{kg}$ per $\mathrm{hr})(11)$. The mean specific activity for each period was considered to be the arithmetic average of the specific activity observed at the beginning and end of the period. Total radioactivity was expressed as percentage of the administered dose.

Two 4-day stool samples were collected from each subject. After homogenization, a portion was combusted to ${ }^{14} \mathrm{CO}_{2}$ and ${ }^{3} \mathrm{H}_{2} \mathrm{O}$ using the Packard oxidizer (Packard Instrument Co., Downers Grove, Ill.) ; in our hands, this instrument gives nearly $100 \%$ recovery of ${ }^{3} \mathrm{H}$ and $80-90 \%$ recovery of ${ }^{14} \mathrm{C}$. Output of ${ }^{14} \mathrm{C}$ in flatus was not measured. Output of ${ }^{14} \mathrm{C}$ in urine was not measured, but in other studies with cholylglycine- $1-{ }^{14} \mathrm{C}$ it has been shown that less than $5 \%$ of the administered ${ }^{14} \mathrm{C}$ is excreted in the urine in $72 \mathrm{hr} .{ }^{1}$

Because 7-dehydroxylation without deconjugation appeared to occur in several subjects, attempts were made to demonstrate this phenomenon in vitro. Fecal samples from two subjects who showed dehydroxylation without deconjugation and from two subjects who did not were used. A portion of each fecal homogenate was added to thioglycollate broth and incubated for $24 \mathrm{hr}$; then $0.1 \mathrm{ml}$ of broth was trans-

${ }^{1}$ Hofmann, A. F., M. N. Tacker, H. Fromm, P. J. Thomas, and L. H. Smith. Unpublished observations. 
ferred to tubes containing $5 \mathrm{ml}$ of thioglycollate broth with $1 \mu$ mole of cholyl-2,4- ${ }^{3} \mathrm{H}$-glycine- $1-{ }^{14} \mathrm{C}$. After anaerobic incubation for $1,3,6$, and $10 \mathrm{hr}$, portions of the broth were removed, diluted with $3 \mathrm{vol}$ of ethanol, heated to $100^{\circ} \mathrm{C}$, and filtered. The filtrate was dried and dissolved in methanol, and the distribution of radioactivity in bile acid fractions was determined by zonal scanning.

\section{CALCULATIONS OF DECONJU- GATION AND EFFICIENCY OF INTESTINAL ABSORPTION}

A simple algebraic model for the enterohepatic circulation of bile acids, with a constant pool size, has been described (12). This model is based on a large, recycling pool of bile acids from which a small, constant fraction is lost during each cycle and replaced by concomitant hepatic synthesis in order to maintain a constant pool size. It assumes that the amount of deconjugation and the efficiency of reabsorption are identical during all cycles.

The pool, $\mathrm{P}$, is secreted $\mathrm{C}$ times daily into the duodenum. The fraction of the pool which is absorbed as cholylglycine or cholic acid $\left(f_{a b s} \cdot p o o l\right)$ is increased by the synthesis of $P\left(1-f_{a b s}\right)$ per cycle or $C \cdot P\left(1-f_{a b s}\right)$ daily, in the steady state with constant pool size.

If some bile acid has been deconjugated by bacterial enzymes in the intestinal lumen before returning to the liver, bile acid conjugation equals the sum of bile acid synthesis plus the amount of unconjugated bile acid returning to the liver. The mole fraction of the pool reabsorbed in conjugated form, $\mathrm{N}_{\text {cons, }}$, does not require conjugation. The unconjugated fraction absorbed during each cycle is equal to $P \cdot f_{a b s}\left(1-N_{\text {cons }}\right)$. Therefore, daily bile acid conjugation equals $C \cdot P\left[\left(1-f_{a b s}\right)+f_{a b s}\right.$ $\left.\left(1-N_{\text {cons }}\right)\right]$ which can be reduced to $C \cdot P\left(1-f_{a b s}\right.$. Neons). Since for cholylglycine the daily bile acid conjugation, and hence deconjugation, is equal to the daily synthesis of the glycine moiety of the cholylglycine, it is possible to calculate the percentage of the cholylglycine pool deconjugated/cycle or per day and the percentage of the cholyl moiety reabsorbed without deconjugation or $7 \alpha$-dehydroxylation.

\section{RESULTS}

${ }^{3} \mathrm{H}:{ }^{14} \mathrm{C}$ ratio in bile and cholylglycine. The change in isotope ratio with time in whole bile reflects the relative loss of glycine- $1-{ }^{14} \mathrm{C}$ and cholyl-2,4- ${ }^{3} \mathrm{H}$ from the enterohepatic circulation. The ratio increased above unity in all subjects (Fig. 1a), indicating that the glycine label is lost more rapidly than the steroid label. As will be shown, ${ }^{8} \mathrm{H}$ in bile was distributed among cholylglycine, deoxycholylglycine, and taurine conjugates and, accordingly, the numerator of the ${ }^{3} \mathrm{H}:{ }^{14} \mathrm{C}$ ratio represents these three bile acids whereas the denominator is predominantly ${ }^{14} \mathrm{C}$ in cholylglycine.
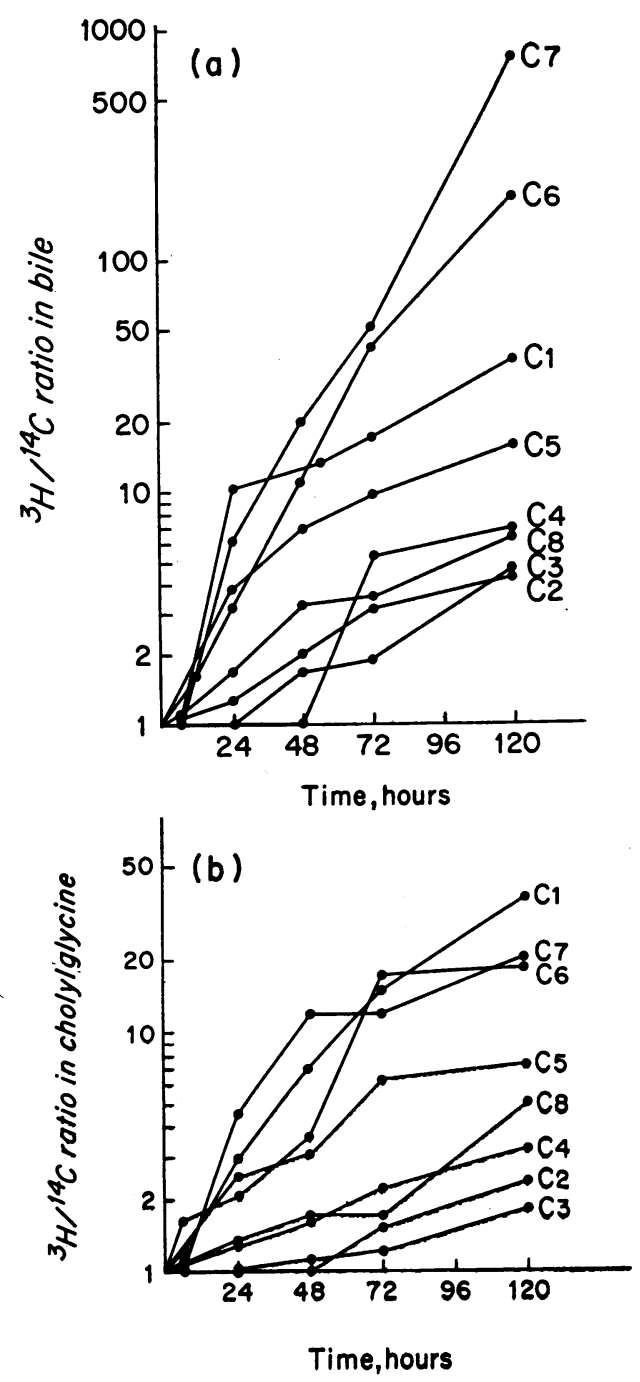

FIGURE $1{ }^{8} \mathrm{H}:{ }^{14} \mathrm{C}$ ratios. (a), in whole bile; $(b)$, in cholylglycine. $C_{1}$ through $C_{8}$ represent different subjects.

The ${ }^{8} \mathrm{H}:{ }^{14} \mathrm{C}$ ratio in cholylglycine (Fig. 1b) was smaller, in all cases, than in bile; here, the numerator contains only the ${ }^{3} \mathrm{H}$ from the cholyl moiety, whereas the denominator is essentially identical to that in bile. The marked increase in the ratio in cholylglycine indicates absorption of the cholyl moiety as such after deconjugation.

Fractional turnover of cholyl- ${ }^{3} \mathrm{H}$ and glycine $-{ }^{14} \mathrm{C}$ moieties of cholylglycine. The mean fractional turnover of the glycine moiety was about three times that of the cholyl moiety (Table I). Accordingly, the calculated daily synthesis of the glycine moiety is more than three times that of the cholyl moiety. A plot of the fractional turnovers of the two moieties against each other (Fig. 2) indicates that four subjects had relatively similar turnover rates of steroid and amino acid moieties, 
Fraction of cholylglycine pool unabsorbed or dehydroxylated per day, $\%$

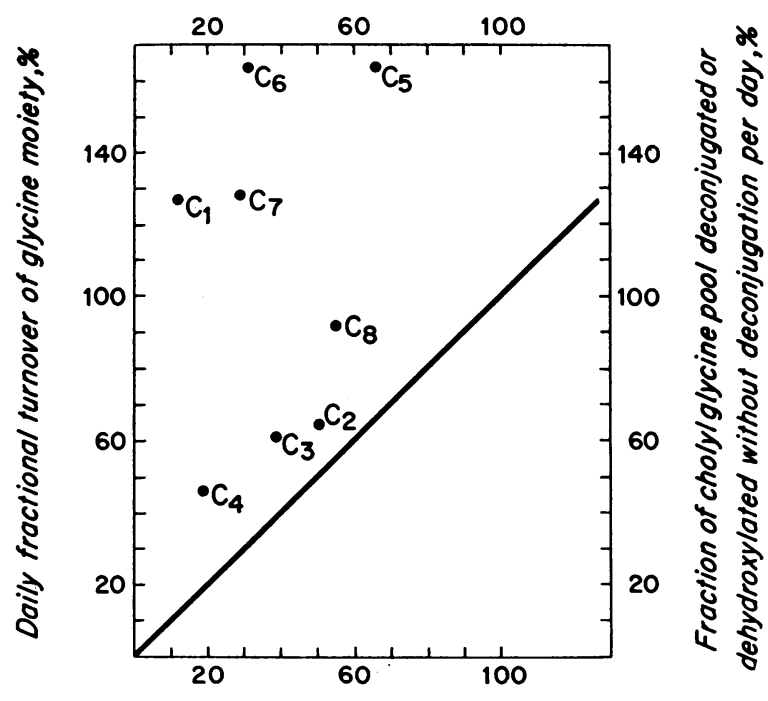

Daily fractional turnover of choly! moiety, $\%$

FIGURE 2 Daily fractional turnover of cholyl moiety plotted against daily fractional turnover of glycine moiety. These are equal (see Changes in cholylglycine pool) to the fraction of cholylglycine pool deconjugated or dehydroxylated per day (per cent) and the fraction of the cholylglycine pool unabsorbed or dehydroxylated per day (per cent) as indicated on the opposite axes. The diagonal is drawn along a line where the daily fractional turnover of the cholyl and glycine moieties are equal and indicates that, in all subjects, the daily fractional turnover of the glycine moiety was greater than that of the cholyl moiety.

whereas in four others the turnover of the amino acid moiety was much more rapid than that of the steroid moiety.

Distribution of ' $H$ in biliary bile acids. There was a progressive increase of ${ }^{3} \mathrm{H}$ in deoxycholylglycine during the first $120 \mathrm{hr}$, with a reciprocal decrease in the percentage of ${ }^{3} \mathrm{H}$ in cholylglycine (Fig. 3 ). The ${ }^{3} \mathrm{H}$ in taurine conjugates reached a maximum of $11.5 \pm 1.5 \%$ at $72 \mathrm{hr}$.

Heterogeneity of subjects. Different patterns of deconjugation, dehydroxylation, and fractional turnover were seen in the eight subjects studied.

In subject $C_{1}$, rapid deconjugation with considerable reabsorption of the liberated cholyl moiety occurred, as evidenced by the rapid increase in the ${ }^{8} \mathrm{H}:{ }^{14} \mathrm{C}$ ratio in bile and in cholylglycine (Fig. $4 a$ ). That the increase of this ratio above unity is due to loss of liberated glycine${ }^{14} \mathrm{C}$ and conservation of cholyl- ${ }^{3} \mathrm{H}$ is shown by comparison of the half-lives of the two moieties: $19 \mathrm{hr}$ for glycine moiety and $59 \mathrm{hr}$ for the cholyl moiety (Table I). Little ${ }^{3} \mathrm{H}$ appeared in deoxycholylglycine in this sub-
TABLE I

Pool Size, Daily Fractional Turnover, and Daily Synthesis in Normal Subjects

\begin{tabular}{|c|c|c|c|c|c|c|c|}
\hline \multirow{2}{*}{$\begin{array}{l}\text { Sub- } \\
\text { ject }\end{array}$} & \multirow{2}{*}{$\begin{array}{c}\text { Cholyl- } \\
\text { glycine } \\
\text { pool }\end{array}$} & \multicolumn{2}{|c|}{$\begin{array}{l}\text { Daily } \\
\text { fractional } \\
\text { turnover }\end{array}$} & \multicolumn{2}{|c|}{ Half-life } & \multicolumn{2}{|c|}{ Synthesis } \\
\hline & & Cholyl & cine & Cholyl & cine & Cholyl & Glycine \\
\hline & mmoles & q & 0 & $h r$ & & $\mathrm{mmol}$ & $s / d a y$ \\
\hline$C_{1}$ & 4.95 & 12 & 128 & 138 & 13 & 0.60 & 6.34 \\
\hline $\mathrm{C}_{2}$ & 4.07 & 50 & 64 & 33 & 26 & 2.04 & 2.60 \\
\hline $\mathrm{C}_{3}$ & 3.02 & 39 & 61 & 43 & 27 & 1.18 & 1.84 \\
\hline $\mathrm{C}_{4}$ & 2.20 & 19 & 46 & 86 & 36 & 0.42 & 1.01 \\
\hline $\mathrm{C}_{5}$ & 2.18 & 66 & 164 & 25 & 10 & 1.44 & 3.58 \\
\hline $\mathrm{C}_{6}$ & 2.75 & 31 & 164 & 54 & 10 & 0.85 & 4.51 \\
\hline $\mathrm{C}_{7}$ & 3.02 & 28 & 128 & 60 & 13 & 0.85 & 3.87 \\
\hline $\mathrm{C}_{8}$ & 1.83 & 55 & 92 & 30 & 18 & 1.01 & 1.68 \\
\hline Mean & 3.00 & 38 & 106 & 59 & 19 & 1.05 & 3.18 \\
\hline $\mathrm{SE}$ & 0.37 & 7 & 17 & 13 & 3 & 0.18 & 0.62 \\
\hline
\end{tabular}

ject's bile, suggesting either that his intestinal flora did not $7 \alpha$-dehydroxylate or, contrary to present concepts (1), that his liver rehydroxylated the deoxycholic acid which was absorbed.

In subject $C_{r}$, rapid deconjugation of cholylglycine also occurred, as is shown by the rapid increase in the ${ }^{3} \mathrm{H}:{ }^{14} \mathrm{C}$ ratio above unity (Fig. $4 b$ ). The conservation of the cholyl moiety was greater than that of the glycine moiety, with half-lives of 60 and $13 \mathrm{hr}$, respectively. However, the ${ }^{8} \mathrm{H}:{ }^{14} \mathrm{C}$ ratio increased more markedly in bile than in cholylglycine because of the presence of much ${ }^{3} \mathrm{H}$ in deoxycholylglycine $(67.7 \%$ at $168 \mathrm{hr})$. This subject therefore showed markedly more 7-dehydroxylation than subject $C_{1}$.

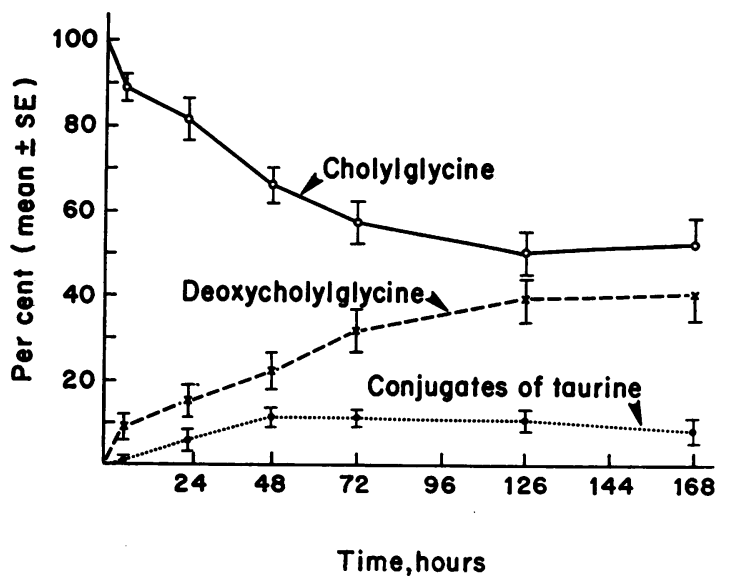

Figure 3 Time course of distribution of ${ }^{3} \mathrm{H}$ among conjugated bile acid classes as mean $\pm_{S E}$ for subjects $C_{1}$ through C8. 

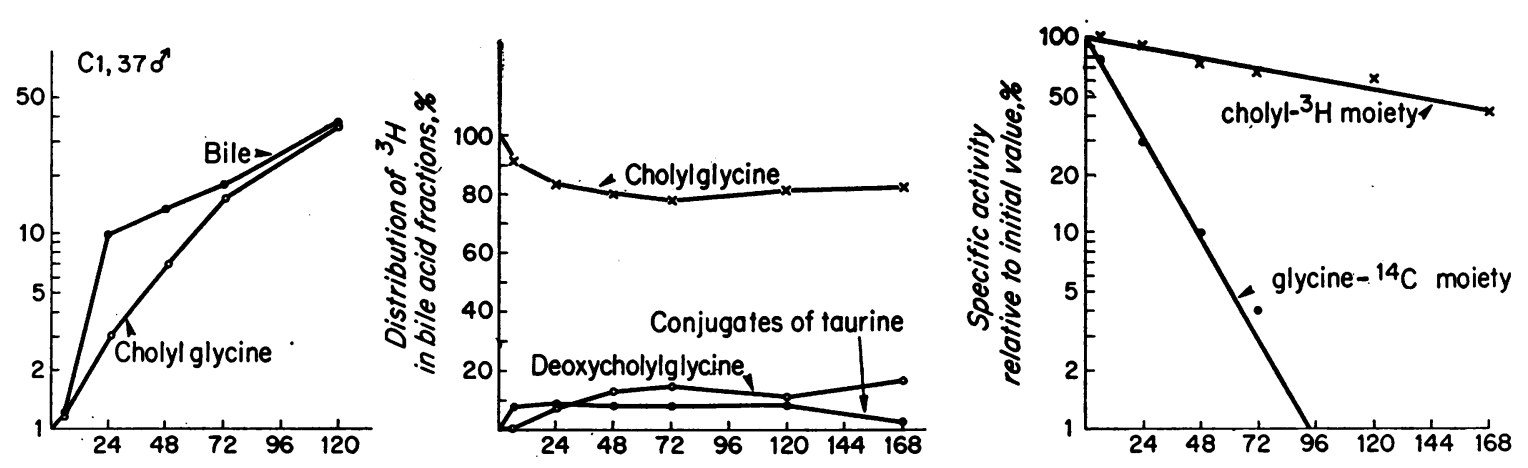

Time, hours
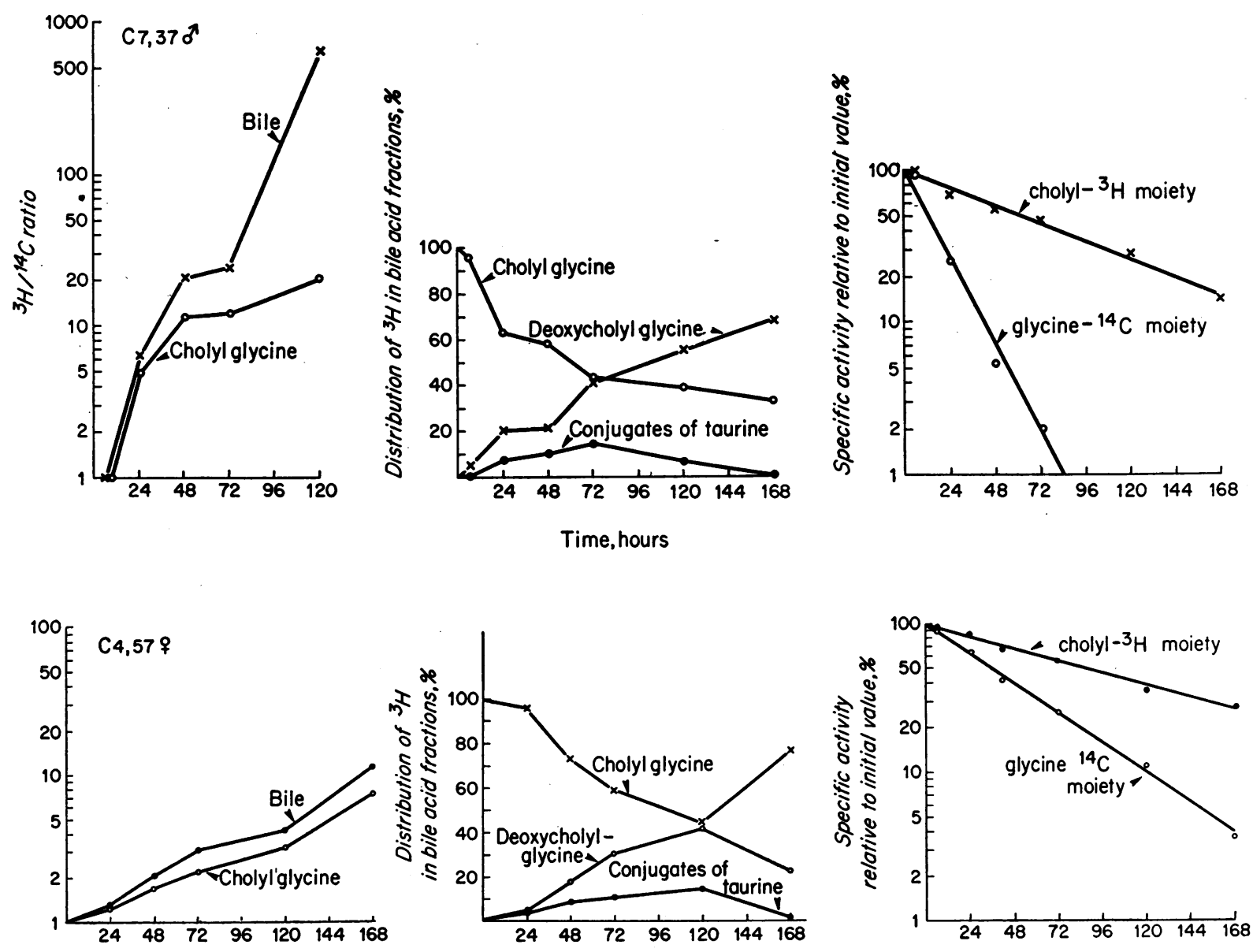

Time, hours

FIgURE 4 Cholylglycine metabolism, showing ${ }^{3} \mathrm{H}:{ }^{14} \mathrm{C}$ ratio in bile and in cholylglycine (left), distribution of ${ }^{3} \mathrm{H}$ among conjugated bile acid classes (center), and specific activity decay curve of cholyl and glycine moieties (right). (a), subject $\mathrm{C}_{1} ;(b)$, subject $\mathrm{C}_{7} ;(c)$, subject $\mathrm{C}_{4}$.

In a third subject, $\mathrm{C}_{4}$, less rapid deconjugation was seen (Fig. $4 c$ ) with a slow, albeit steady, increase in the ${ }^{3} \mathrm{H}:{ }^{14} \mathrm{C}$ ratio in bile and in cholylglycine. The half- life for the glycine moiety was still shorter than that for the cholyl moiety ( 36 and $86 \mathrm{hr}$, respectively), but for both moieties the half-lives were well above the means 


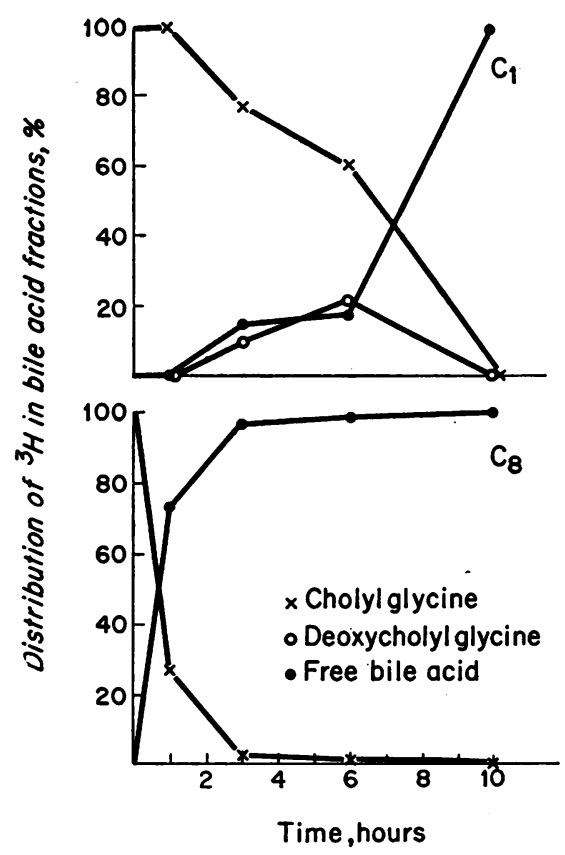

Figure 5 Time course of distribution of ${ }^{3} \mathrm{H}$ among conjugated bile acid classes after incubation of cholyl-2,4- ${ }^{3} \mathrm{H}$ glycine with fecal organisms derived from subjects $C_{1}$ and $\mathrm{C}_{8 .}$ The appearance of radioactivity in deoxycholylglycine (open circles) indicates 7-dehydroxylation without deconjugation.

for the eight subjects. Almost $42 \%$ of the ${ }^{3} \mathrm{H}$ was in deoxycholylglycine at $120 \mathrm{hr}$, but this decreased to $22.5 \%$ at $168 \mathrm{hr}$.

7-Dehydroxylation without deconjugation. In vivo. In three subjects, $\mathrm{C}_{1}, \mathrm{C}_{6}$, and $\mathrm{C}_{7},{ }^{14} \mathrm{C}$ appeared in deoxycholylglycine, based on chromatography, at specific times during the study (Table II). It was detectable in $\mathrm{C}_{1}$ from 24 to $120 \mathrm{hr}$ after administration of cholyl-2,4- ${ }^{3} \mathrm{H}-$ glycine-1 ${ }_{-1}^{14} \mathrm{C}$. In $\mathrm{C}_{6}$ and $\mathrm{C}_{7}$ it was present only at 6 and $24 \mathrm{hr}$. In the five other subjects of this study, no ${ }^{14} \mathrm{C}$ was detected in deoxycholylglycine at any time.

TABLE II

Per Cent of ${ }^{14} \mathrm{C}$ in Deoxycholylglycine Fraction of Bile

\begin{tabular}{lrrrrrr}
\hline & \multicolumn{7}{c}{ Time interval } \\
\cline { 2 - 7 } ject & 6 & 24 & 48 & 72 & 120 & 168 \\
\hline & & & & $h r$ & & \\
$\mathrm{C}_{1}$ & 0 & 14 & 20 & 22 & 14 & 0 \\
$\mathrm{C}_{6}$ & 25 & 11 & 0 & 0 & 0 & 0 \\
$\mathrm{C}_{7}$ & 3 & 7 & 0 & 0 & 0 & 0 \\
Gb $_{9}^{*}$ & 1 & 1 & 4 & 10 & 5 & 0 \\
\hline
\end{tabular}

* A 55-yr old woman who had had cholecystectomy 9 yr before this study.
TABLE III

Recovery of ${ }^{3} \mathrm{H}$ and ${ }^{14} \mathrm{C}$ in Stool and Breath in $168 \mathrm{Hr}$

\begin{tabular}{|c|c|c|c|}
\hline \multirow{2}{*}{$\begin{array}{l}\text { Sub- } \\
\text { ject }\end{array}$} & \multirow{2}{*}{$\frac{{ }^{3} \mathrm{H}}{\text { Stool }}$} & \multicolumn{2}{|c|}{${ }^{14} \mathrm{C}$} \\
\hline & & Stool & Breath \\
\hline & $\%$ dose & \multicolumn{2}{|c|}{$\%$ dose } \\
\hline $\mathrm{C}_{1}$ & 33 & 2.0 & 71 \\
\hline $\mathrm{C}_{2}$ & 53 & 16.9 & 35 \\
\hline $\mathrm{C}_{3}$ & 50 & 6.0 & 34 \\
\hline$C_{4}$ & 38 & 6.9 & 36 \\
\hline $\mathrm{C}_{5}$ & 67 & 6.3 & 63 \\
\hline $\mathrm{C}_{6}$ & 67 & 3.5 & 65 \\
\hline $\mathrm{C}_{7}$ & 65 & 5.0 & 56 \\
\hline $\mathrm{C}_{8}$ & 68 & 3.3 & 54 \\
\hline Mean & 55 & 6.2 & 52 \\
\hline SE & 5 & 1.6 & 5 \\
\hline
\end{tabular}

After $20 \mu \mathrm{Ci}$ of glycine-1- ${ }^{14} \mathrm{C}$ had been given to one subject $\left(\mathrm{C}_{8}\right)$, no cholylglycine- $1-{ }^{14} \mathrm{C}$ could be detected in the bile 6 and $24 \mathrm{hr}$ later. Thus, it seems improbable that any significant reincorporation of glycine- $1-{ }^{14} \mathrm{C}$ occurred when $10 \mu \mathrm{Ci}$ of cholylglycine- $1-{ }^{14} \mathrm{C}$ was administered.

In vitro. Stool samples from subjects $C_{1}$ and $C_{7}$ (dehydroxylation without deconjugation) and subjects $\mathrm{C}_{3}$ and $\mathrm{C}_{8}$ (no glycine label in deoxycholylglycine) were incubated with cholyl-2,4- ${ }^{3} \mathrm{H}$-glycine- $1-{ }^{14} \mathrm{C}$ for $1,3,6$, and $10 \mathrm{hr}$. Deoxycholylglycine derived from cholylglycine-that is, labeled with ${ }^{14} \mathrm{C}$-was found after incubation with stool from $C_{1}$ by thin-layer chromatography, but none appeared after incubation of stool from $\mathrm{C}_{7}$, who had also shown in vivo 7-dehydroxylation without deconjugation, or from $\mathrm{C}_{3}$ and $\mathrm{C}_{8}$ (Fig. 5).

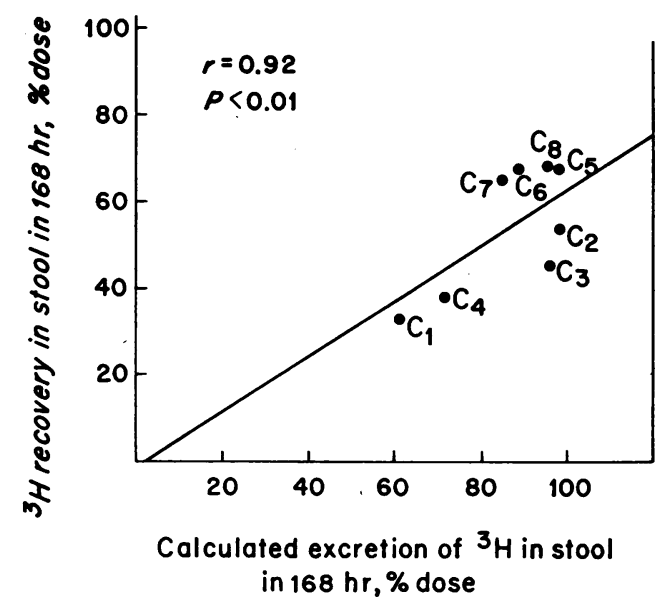

FIgure 6 Cumulative fecal excretion of ${ }^{3} \mathrm{H}$ in $168 \mathrm{hr}$, expressed as percentage of administered dose, calculated from fractional turnover rate of ${ }^{3} \mathrm{H}$ cholyl moiety plotted against recovery of ${ }^{3} \mathrm{H}$ in stool in that period. 
Recovery of ${ }^{3} \mathrm{H}$ and ${ }^{14} \mathrm{C}$. In stool, the mean ( $\pm \mathrm{SE}$ ) recoveries by $168 \mathrm{hr}$ were $55 \pm 5 \%$ for ${ }^{3} \mathrm{H}$ and $6.2 \pm 1.6 \%$ for ${ }^{14} \mathrm{C}$ (Table III). By contrast, in the breath the recovery of ${ }^{14} \mathrm{C}$ was $52 \pm 5 \%$. Of the ${ }^{14} \mathrm{C}$ recovered in the breath, $22 \pm 32 \%$ was recovered in the first $24 \mathrm{hr}$.

A significant correlation was found between the excretion of ${ }^{3} \mathrm{H}$ in stool calculated from the fractional turnover rate of the ${ }^{3} \mathrm{H}$ cholyl moiety and the actual recovery of ${ }^{3} \mathrm{H}$ in the stool ( $r=0.92 ; P=0.001$ ) (Fig. 6). The recovery of ${ }^{3} \mathrm{H}$ was less than predicted from the daily fractional turnover rate of the cholyl moiety because some cholic acid is 7-dehydroxylated and reabsorbed, thus conserving the steroid moiety as deoxycholic, but not cholic, acid, and because some ${ }^{3} \mathrm{H}$ is removed from the steroid nucleus and enters body water.

A significant correlation also was found between the daily fractional turnover rate of the glycine moiety and 24-hr ${ }^{14} \mathrm{CO}_{2}$ excretion in the breath $(r=0.95 ; P=0.001)$ (Fig. 7). The daily fractional turnover of the glycine moiety equals $1.4+4.7 \%$ of dose excreted in ${ }^{14} \mathrm{CO}_{2}$ in $24 \mathrm{hr}$.

Changes in cholylglycine pool. Daily loss due to 7-dehydroxylation or failure to reabsorb. Loss of the cholyl moiety of cholylglycine can be due to 7-dehydroxylation with or without reabsorption of the resultant deoxycholic acid or deoxycholylglycine or to failure to reabsorb cholic acid or cholylglycine. In the mathematical model described in Methods, the losses due to both of these factors are equal to the daily fractional turnover rate of the cholyl moiety of cholylglycine. Thus, the mean ( $\pm \mathrm{SE}$ ) percentage of the cholylglycine pool lost, for either reason, is $38 \pm 7 \% /$ day or about $6 \pm 1 \% /$ cycle for 6 cycles/ day.

Daily deconjugation. The percentage, per day, of the cholylglycine pool deconjugated or 7-dehydroxylated without deconjugation is equal to the daily fractional turnover rate of the glycine moiety of cholylglycine in the model. Thus, $106 \pm 17 \%$ of the pool is deconjugated or 7-dehydroxylated without deconjugation per day or about $18 \pm 3 \% /$ cycle for 6 cycles/day.

\section{DISCUSSION}

Despite considerable variation in the fractional turnover rates of both steroid and amino acid moieties among subjects, glycine degradation (and synthesis) was more rapid than cholic acid loss and 7-dehydroxylation in each subject. Cleavage of the amide bond of cholylglycine is mediated exclusively by bacterial enzymes (13-16), but the site of such bacterial deconjugation was not indicated by this study.

Biotransformation of glycine and cholyl moieties. The ${ }^{14} \mathrm{C}$ present in glycine- $1-{ }^{14} \mathrm{C}$ was rapidly converted to ${ }^{14} \mathrm{CO}_{2}$ after liberation from cholylglycine- $1-{ }^{14} \mathrm{C}$; this conversion may be caused by bacterial or tissue enzymes which mediate an exchange between carboxyl

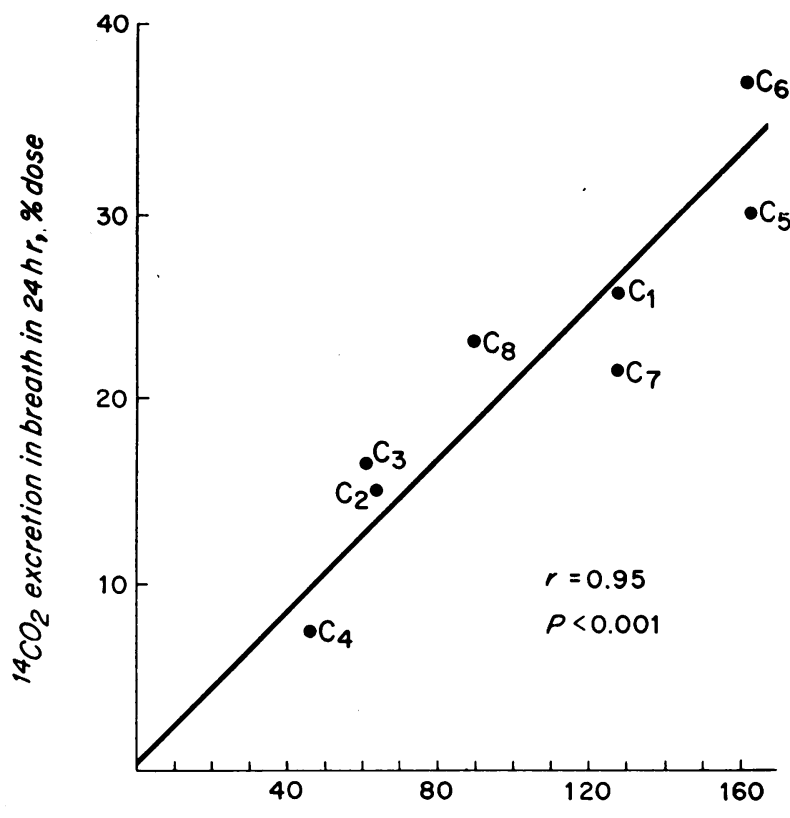

Daily fractional turnover of glycine moiety, $\%$

FIGURE 7 Daily fractional turnover of glycine moiety plotted against ${ }^{14} \mathrm{CO}_{2}$ excretion in breath in $24 \mathrm{hr}$ as percentage of administered dose. The cumulative excretion of ${ }^{14} \mathrm{CO}_{2}$ in this period was calculated by multiplying the mean $\mathrm{CO}_{2}$ specific activity between intervals at which this was measured by the endogenous production of $\mathrm{CO}_{2}(9 \mathrm{mmoles} / \mathrm{kg}$ per $\mathrm{hr})$.

carbon and that of bicarbonate in the medium $(17,18)$. The site of such an enzyme-mediated exchange, however, is not indicated in our study. In contrast to glycine-2- ${ }^{14} \mathrm{C}$, glycine- $1-{ }^{14} \mathrm{C}$ is known to show little incorporation into tissue proteins $(18,19)$ and to be rapidly excreted in breath $(11,20)^{1}$; biotransformations other than conversions to ${ }^{14} \mathrm{CO}_{2}$ were not examined. Metabolism of the nitrogen atom of the glycine moiety has been well characterized (21-23) but varies according to the route of administration (24). The fate of the glycine nitrogen when glycine is attacked by bacteria in the intestinal lumen is unknown.

${ }^{3} \mathrm{H}$ from the cholyl moiety appeared rapidly in deoxycholylglycine in all eight subjects. However, the rate of bacterial production or of absorption (or both) of deoxycholic acid appeared to differ greatly, since the percentage of ${ }^{8} \mathrm{H}$ in deoxycholylglycine ranged from 2.6 to 67.4 on the 7 th day. No other bile acids containing ${ }^{8} \mathrm{H}$ were identified.

The rate of 7-dehydroxylation of cholic acid varied greatly among the eight subjects. Like deconjugation. 7 -dehydroxylation is caused by intestinal bacterial enzymes (25). The organisms that cause 7-dehydroxylation are strict anaerobes and therefore are unlikely to exist in large numbers in the ileum of healthy per- 
sons, where, even distally, aerobic bacteria predominate over anaerobes (26). On the other hand, while deconjugation is caused mainly by anaerobes (15) it may also be caused by aerobic bacteria (27). It is therefore possible that those patients who absorbed large amounts of free cholic acid had deconjugating but not dehydroxylating bacteria in their ileum, while those who formed deoxycholic acid more rapidly had deconjugating bacteria only in a site where 7-dehydroxylating bacteria were also present-namely, the colon.

Kinetics and route of excretion. The radioactivity present in cholylglycine- $1{ }^{14} \mathrm{C}$ was excreted predominantly in breath, with about $50 \%$ of the administered dose recovered in the breath in 1 wk.

The pool size and synthesis rates of the cholyl moiety of cholylglycine agree closely with those reported for cholic acid pool size and synthesis rates $(1,8,25,28-$ 30 ). The latter should be about one-third larger since they include cholyltaurine. To our knowledge, our data on the synthesis of the glycine moiety are the first to be reported.

Dehydroxylation without deconjugation. In four subjects, ${ }^{14} \mathrm{C}$ appeared in deoxycholylglycine. Since administered glycine-1 $1{ }^{14} \mathrm{C}$ itself did not label the cholylglycine pool, in these subjects the labeled deoxycholylglycine must have come from cholylglycine that had been 7-dehydroxylated without deconjugation. The in vitro demonstration of 7-dehydroxylation without deconjugation complements the experiments of Aries and Hill (31) who prepared cell-free extracts of pure strains of enteric bacteria with 7-dehydroxylating activity toward cholic and chenodeoxycholic acids but found that these extracts failed to 7-dehydroxylate cholylglycine or cholylglycine methyl ester. Thus, 7dehydroxylation without deconjugation has only been observed in vivo and in vitro when a mixed flora was present.

Subject heterogeneity. Our paper presents the first measurements of the extent of bacterial deconjugation of the bile acid pool during enterohepatic cycling in healthy subjects. Striking heterogeneity in the metabolism of cholylglycine was observed with fractional turnover rates of the cholyl moiety ranging from 19 to $66 \%$ and of the glycine moiety, from 46 to $164 \%$. Similar heterogeneity existed in the observed biotransformation of the cholyl moiety, with the maximal amount of ${ }^{8} \mathrm{H}$ appearing in deoxycholylglycine ranging from 9 to $67 \%$. Moreover, we observed that there was no apparent correlation between deconjugation (reflected by the fractional turnover rate of the glycine moiety of cholylglycine) and 7-dehydroxylation (reflected by the biotransformation of cholic acid to deoxycholic acid), although both these phenomena are due largely to enteric bacteria. The heterogeneity pre- sumably reflects differences in intestinal flora as well as in absorptive capacity for free and conjugated bile acids.

Application to disease. The high correlation between the daily fractional turnover rate of the glycine moiety of labeled cholylglycine and ${ }^{14} \mathrm{CO}_{2}$ output suggests that the ${ }^{14} \mathrm{CO}_{3}$ output may be used to predict the turnover of the glycine moiety of cholylglycine. According to our study, the daily fractional turnover of the glycine moiety is about five times the percentage of the dose of cholylglycine- $1{ }^{14} \mathrm{C}$ excreted as ${ }^{14} \mathrm{CO}_{2}$ in the breath in $24 \mathrm{hr}$. Measurement of ${ }^{14} \mathrm{CO}_{2}$ production after administration of cholylglycine-1 $-{ }^{14} \mathrm{C}$ has recently been shown to be a useful method for detecting patients with increased bile acid deconjugation and is the basis of a simple breath test for altered bile acid metabolism $(32,33)$.

Patients with bacterial overgrowth or bile acid malabsorption caused by ileal dysfunction have greatly increased turnover of bile acid glycine based on ${ }^{14} \mathrm{CO}_{2}$ measurements after administration of cholylglycine-1${ }^{14} \mathrm{C}(32,33)$. Since such patients have predominantly glycine-conjugated bile acids in bile $(34,35)$, they must have greatly increased synthesis rates of bile acid glycine. This greatly increased synthesis may be related to the hyperoxaluria which is seen in some of these patients (36) since administration of taurine, which decreases glycine conjugation by increasing conjugation with taurine, also abolishes the hyperoxaluria $(37,38)$ in some instances.

\section{ACKNOWLEDGMENTS}

This investigation was supported in part by Research Grant AM-6908 from the National Institutes of Health, U. S. Public Health Service.

\section{REFERENCES}

1. Danielsson. H. 1963. Present status of research on catabolism and excretion of cholesterol. Adv. Lipid Res. 1 : 335 .

2. Norman, A. 1970. Metabolism of glycocholic acid in man. Scand. J. Gastroenterol. 5 : 231.

3. Garbutt, J. T., R. M. Wilkins, L. Lack, and M. P. Tyor. 1970. Bacterial modification of taurocholate during enterohepatic recirculation in normal man and patients with small intestinal disease. Gastroenterology. 59: 553.

4. Hofmann, A. F., P. A. Szczepanik, and P. D. Klein. 1968. Rapid preparation of tritium-labeled bile acids by enolic exchange on basic alumina containing tritiated water. J. Lipid Res. 9: 707.

5. Norman, A. 1955. XXXIV. Preparation of conjugated bile acids using mixed carboxylic acid anhydrides: bile acids and steroids. 34. Ark. Kemi. 8: 331.

6. Snyder, F., and H. Kimble. 1965. An automatic zonal scraper and sample collector for radioassay of thinlayer chromatograms. Anal. Biochem. 11: 510 . 
7. Stempfel, R. S., Jr., and J. B. Sidbury, Jr. 1964. Studies with hydroxysteroid dehydrogenases. I. A simplified method for the enzymatic estimation of 3- and 17hydroxysteroids. J. Clin. Endocrinol. Metab. 24: 367.

8. Lindstedt, S. 1957. The turnover of cholic acid in man: bile acids and steroids 51. Acta Physiol. Scand. 40: 1 .

9. Abt, A. F., and S. L. von Schuching. 1966. Fat utilization test in disorders of fat metabolism: a new diagnostic method applied to patients suffering with malabsorption syndrome, chronic pancreatitis, and arteriosclerotic cardiovascular disease. Johns Hopkins Med.J. 119: 316.

10. Kaihara, S., and H. N. Wagner, Jr. 1968. Measurement of intestinal fat absorption with carbon-14 labeled tracers. J. Lab. Clin. Med. 71: 400.

11. Winchell, H. S., H. Stahelin, N. Kusubov, B. Slanger, M. Pollycove, and J. H. Lawrence. 1970. Kinetics of $\mathrm{CO}_{2}-\mathrm{HCO}_{3}$ minus in normal adult males. J. Nucl. Med. $11: 711$.

12. Hofmann, A. F. 1966. A physicochemical approach to the intraluminal phase of fat absorption. Gastroenterology. $50: 56$.

13. Norman, A., and O. A. Widström. 1964. Hydrolysis of conjugated bile acids by extracellular. enzymes present in rat intestinal contents. Proc. Soc. Exp. Biol. Med. 117: 442 .

14. Playoust, M. R., and K. J. Isselbacher. 1964. Studies on the transport and metabolism of conjugated bile salts by intestinal mucosa. J. Clin. Invest. 43: 467.

15. Aries, V., and M. J. Hill. 1970. Degradation of steroids by intestinal bacteria. I. Deconjugation of bile salts. Biochim. Biophys. Acta. 202: 526.

16. Norman, A., and R. Grubb. 1955. Hydrolysis of conjugated bile acids by clostridia and enterococci: bile acids and steroids 25. Acta Pathol. Microbiol. Scand. $36: 537$.

17. Klein, S. M., and R. D. Sagers. 1966. Glycine metabolism. I. Properties of the system catalyzing the exchange of bicarbonate with the carboxyl group of glycine in Peptococcus glycinophilus. J. Biol. Chem. 241 : 197.

18. Richert, D. A., R. Amberg, and M. Wilson. 1962. Metabolism of glycine by avian liver. J. Biol. Chem. 237: 99.

19. Tada, K., K. Narisawa, T. Yoshida, T. Konno, Y. Yokoyama, H. Nakagawa, K. Tanno, K. Mochizuki, and T. Arakawa. 1969. Hyperglycinemia: a defect in glycine cleavage reaction. Tohoku J. Exp. Med. 98: 289.

20. Ando, T., W. L. Nyhan, T. Gerritsen, L. Gong, D. C. Heiner, and P. F. Bray. 1968. Metabolism of glycine in the nonketotic form of hyperglycinemia. Pediat. Res. 2 : 254.

21. Shemin, D., and D. Rittenberg. 1946. The biological utilization of glycine for the synthesis of the protoporphyrin of hemoglobin. J. Biol. Chem. 166: 621 .
22. Shemin, D., and D. Rittenberg. 1946. The life span of the human red blood cell. J. Biol. Chem. 166: 627 .

23. Choitz, H. C., D. Kurrie, and O. H. Gaebler. 1963. Utilization of glycine nitrogen at various levels of glycine intake. J. Nutr. 80: 365 .

24. Gaebler, O. H., and H. C. Choitz. 1969. Comparative utilization of glycine- $\mathrm{N}^{15}$ administered orally or parenterally. Metab. (Clin. Exp.), 18: 416.

25. Nilsson, S., and T. Scherstén. 1969. Importance of bile acids for phospholipid secretion into human hepatic bile. Gastroenterology. 57: 525.

26. Gorbach, S. L. 1971. Intestinal microflora. Gastroenterology. $60: 1110$.

27. Yesair, D. W., and P. Himmelfarb. 1970. Hydrolysis of conjugated bile acids by cell-free extracts from aerobic bacteria. Appl. Microbiol. 19: 295.

28. Heaton, K. W., W. I. Austad, L. Lack, and M. P. Tyor. 1968. Enterohepatic circulation of $\mathrm{C}^{14}$-labeled bile salts in disorders of the distal small bowel. Gastroenterology. $55: 5$.

29. Vlahcevic, Z. R., J. R. Miller, J. T. Farrar, and L. Swell. 1971. Kinetics and pool size of primary bile acids in man. Gastroenterology. 61: 85.

30. Danzinger, R. G., A. F. Hofmann, L. J. Schoenfield, and J. L. Thistle. 1971. Altered bile acid metabolism in patients with cholesterol cholelithiasis. J. Clin. In vest. 50: 24a. (Abstr.)

31. Aries, V., and M. J. Hill. 1970. Degradation of steroids by intestinal bacteria. II. Enzymes catalysing the oxidoreduction of the $3 \alpha-, 7 \alpha-$ and $12 \alpha$-hydroxyl groups in cholic acid, and the dehydroxylation of the 7-hydroxyl group. Biochim. Biophys. Acta. 202: 535.

32. Fromm, H., and A. F. Hofmann. 1971. Breath test for altered bile acid metabolism. Lancet. 2: 621.

33. Sherr, H. P., Y. Sasaki, A. Newman, J. G. Banwell, H. N. Wagner, Jr., and T. R. Hendrix. 1971. Detection of bacterial deconjugation of bile salts by a convenient breath-analysis technic. N. Engl. J. Med. $285: 656$.

34. Garbutt, J. T., K. W. Heaton, L. Lack, and M. P. Tyor. 1969. Increased ratio of glycine- to taurine-conjugated bile salts in patients with ileal disorders. Gastroenterology. 56: 711 .

35. McLeod, G. M., and H. S. Wiggins. 1968. Bile-salts in small intestinal contents after ileal resection and in other malabsorption syndromes. Lancet. 1: 873.

36. Hofmann, A. F., P. J. Thomas, L. H. Smith, and J. T. McCall. 1970. Pathogenesis of secondary hyperoxaluria in patients with ileal resection and diarrhea. Gastroenterology. 58 : 960. (Abstr.)

37. Dowling, R. H., G. A. Rose, and D. J. Sutor. 1971. Hyperoxaluria and renal calculi in ileal disease. Lancet. 1: 1103.

38. Admirand, W. H., D. L. Earnest, and H. E. Williams. 1971. Hyperoxaluria and bowel disease. Trans. Ass. Amer. Physicians Philadelphia. 84: 307. 